\title{
5-Fluorouracil/Salicylic Acid Topical Solution
}

National Cancer Institute

\section{Source}

National Cancer Institute. 5-Fluorouracil/Salicylic Acid Topical Solution. NCI Thesaurus.

Code C97131.

A topical formulation containing $0.5 \%$ of antimetabolite 5 -fluorouracil (5-FU) and $10 \%$ of salicylic acid, with potential antimitotic and keratolytic activity. Upon cutaneous application, 5-FU in the 5-fluorouracil/salicylic acid topical solution impedes pyrimidine metabolism thereby inhibiting cell growth, while the salicylic acid induces antiinflammatory response and results in keratolytic effect. This may result in the breakdown of keratinocytes and prevent proliferation of keratinocytes locally. 